\title{
POSITIVE PSEUDO-SYMMETRIC SOLUTIONS FOR A NONLOCAL $p$-LAPLACIAN BOUNDARY VALUE PROBLEM
}

\author{
L. X. Truong, P. D. Phung and B. T. Quan
}

Abstract. This paper is devoted to the study of the following nonlocal $p$-Laplacian functional differential equation

$$
-\left(\phi_{p}\left(x^{\prime}(t)\right)\right)^{\prime}=\frac{\lambda f\left(t, x(t), x^{\prime}(t)\right)}{\left(\int_{0}^{1} f\left(s, x(s), x^{\prime}(s)\right) d s\right)^{n}}, \quad 0<t<1,
$$

subject to multi point boundary conditions. We obtain some results on the existence of at least one (when $n \in \mathbb{Z}^{+}$) or triple (when $n=0$ ) pseudo-symmetric positive solutions by using fixedpoint theory in cone.

Mathematics subject classification (2010): 34B07, 34B10, 34B18, 34B27.

Keywords and phrases: boundary value problem, pseudo-symmetric solutions, p-Laplacian, LeggettWilliams fixed point theorem, Guo-Krasnoselskii fixed point theorem.

\section{REFERENCES}

[1] M. R. S. AMmi, D. F. M. TORRES, Existence of positive solutions for nonlocal p-Laplacian thermistor problems on time scales, J. Inequalities in Pure and Apll. Math., 8 (2007), 1-10.

[2] R.I. AVERY, J. HENDERSON, Three symmetric positive solutions for a second order boundary value problem, Appl. Math. Lett., 13 (2000), 1-7.

[3] R. AVERY, J. HENDERSON, Existence of three positive pseudo-symmetric solutions for a one dimensional p-Laplacian operator, J. Math. Anal. Appl., 277 (2003), 395-404.

[4] R.P. Agarwal, H. L“U, D. O’Regan, Eigenvalues and the one-dimensional p-Laplacian, J. Math. Anal. Appl., 266 (2002), 383-340.

[5] Y. Guo, W. GE, Three positive solutions for the one-dimensional p-Laplacian, J. Math. Anal. Appl., 286 (2003), 491-508.

[6] Y. Guo, W. GE, Positive solutions for three point boundary value problems with dependence on the first order derivative, J. Math. Anal. Appl., 290 (2004), 291-301.

[7] V.A. IL'In, E.I. MoISEEv, Nonlocal boundary value problem of the rst kind for a Sturm-Liouville operator, Differ. Equations, 23 (1987), 979-987.

[8] V.A. IL'IN, E.I. MoISEEV, Nonlocal boundary value problem of the first kind for the Sturm-Liouville operator in the differential and difference treatment, Differ. Equations, 23 (1987), 1198-1207.

[9] M. A. KRASNOSEL'SKII, Positive solution of Operator Equations, Noordho, Groningen, 1964.

[10] R.W. LegGeTt, L.R. Williams, Multiple positive fixed points of nonlinear operators on ordered Banach spaces, Indiana Univ. Math. J., 28 (1979), 673-688.

[11] D. MA, W. GE, Existence and iteration of positive pseudo-symmetric solutions for a three-point second-order p-Laplacian BVP, Appl. Math. Lett., 20 (2007), 1244-1249.

[12] B. Sun, W. GE, Successive iteration and positive pseudo-symmetric solutions for a three-point second-order p-Laplacian boundary value problems, Appl. Math. Comput., 188 (2007), 1772-1779. 
[13] Y. H. Su, W. Wu, X. YAng, Existence Theory for Pseudo-Symmetric Solution to p-Laplacian Differential Equations Involving Derivative, Abstract and Applied Analysis, 2011 (2011), Article ID 182831, 19 pages.

[14] L. X. Truong, L. T. P. NGoc, N. T. Long, Positive solutions for an m-point boundary value problem, Electron. J. Differential Eqns., 111 (2008), 1-11.

[15] L.X. TRuong, P.D. Phung, Existence of positive solutions for a multi-point four-order boundaryvalue problem, Electron. J. Differential Eqns., 119 (2011), 1-10.

[16] J.Y. WANG, The existence of positive solutions for the one-dimensional p-laplacian, Proc. Amer. Math. Soc., 125 (1997), 2275-2283.

[17] Y. YANG, Existence of positive pseudo-symmetric solutions for one dimensional p-Laplacian boundary value problem, Electron. J. Differential Eqns., 70 (2007), 1-6. 